\title{
Rural surgery in Guinea Bissau: an experience of Doctors Worldwide Turkey
}

\author{
Orhan Alimoglu, ${ }^{1}$ Julide Sagiroglu,${ }^{1}$ Tunc Eren, ${ }^{1}$ Kerem Kinik ${ }^{2}$ \\ ${ }^{1}$ Department of General Surgery, Istanbul Medeniyet University School of Medicine, Istanbul, Turkey \\ 2Department of Disaster Medicine, Bezm-i Alem University School of Medicine, Vakif Gureba Hospital, Istanbul, Turkey
}

\begin{abstract}
OBJECTIVE: In Africa, there is critical shortage of surgeons. Majority of the surgeons work in urban centers, and almost none of them is working in the rural areas. This study documents surgical interventions performed in Guinea-Bissau by Doctors Worldwide Turkey.
\end{abstract}

METHODS: A group of surgeons from the Doctors Worldwide Turkey performed various surgical interventions in the Simao Mendes, Gabu and Bafata community hospitals. Demographics, surgical methods, anesthesia techniques and complications were recorded.

RESULTS: Sixty- four procedures were undertaken between 5-16 February 2010 and 6-11 May 2011. The patient population consisted of 47 male (82.5\%) and 10 female (17.5\%) patients with a mean age of 44.5 (range: $6-81$ ) years. Five emergency cases were observed. Hartmann's procedure for rectal carcinoma; modified radical mastectomy for breast carcinoma; 2 right total thyroidectomies, 1 bilateral subtotal thyroidectomy; 2 incisional hernia repairs with mesh, 1 breast lumpectomy, 3 mass excisions, 2 keloidectomies, and various techniques of hernia repair for 35 inguinal hernias ( 4 bilateral, 3 strangulated and 2 coexisting with hydrocele), Winkelmann's procedure for 5 hydroceles (1 bilateral), and unilateral orchiectomy for 1 bilateral hydrocele were recorded. Sixteen patients received general (23.5\%), 23 spinal (33.8\%), 7 epidural (10.3\%), 15 local (22.1\%), and 7 ketamine $(10.3 \%)$ anesthesia. There was no mortality.

CONCLUSION: Surgical diseases, majority of which are hernias threaten public health in underdeveloped regions of Africa. Blitz surgery may be an efficient temporary solution.

Keywords: Doctors Worldwide Turkey; Guinea-Bissau; rural surgery.

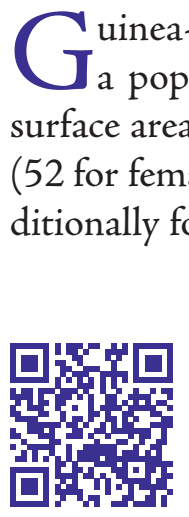

ity of financial sources are spent for research and treatment of infectious diseases. During the recent years, public health services have shown remarkable tendency towards improving the quality of services in surgical diseases $[1,2]$.

Received: August 31, 2015 Accepted: November 22, 2015 Online: December 25, 2015

Correspondence: Dr. Orhan ALIMOGLU. Istanbul Medeniyet Universitesi Tip Fakultesi, Genel Cerrahi Anabilim Dali, Istanbul, Turkey.

Tel: +90 216 - 2803333 e-mail: orhanalimoglu@gmail.com

(c) Copyright 2015 by Istanbul Northern Anatolian Association of Public Hospitals - Available online at www.kuzeyklinikleri.com 
Trauma, labor and labor-related bleeding are the major causes of mortality as well as chronic diseases. Recent survey in these countries revealed that surgery is an efficient and cost effective way of treatment with the help of collaboration between international organizations, academic institutions, professional societies, humanitarian aid foundations and non-governmental organizations, surgical associations and public health organizations started to co-act on this issue. Thus, surgical diseases are being evaluated as public health problems.

Global Burden of Surgical Disease Working Group was established in 2008 and started to work in order to approach global surgical diseases within the conventional public health perspective [3]. Education of the local medical staff is apparently within these proceedings.

Doctors Worldwide (DWW) Turkey is a nongovernmental organization which was established in 2004 by a group of doctors in Turkey in order to help and medically support people who are deprived of health care services because of war, famine, asylum and natural disasters all around the world. Doctors Worldwide Turkey expanded their team and domain in time and also started to provide preventive health services, education and help to sustain health systems in rural areas.

Since they were first established, DWW Turkey has brought medical as well as humanitarian aid to suffering communities of more than 40 countries in 4 continents.

Sub-Saharan African countries possess only 2\% of the medical aid sources of the world, while suffering from $25 \%$ of the disease load of the globe. In the East Africa, there is only 1 surgeon per 400.000 population [4].

Doctors Worldwide (DWW), Republic of Turkey Ministry of Health, Turkish Collaboration and Development Department carried a collaborative act in Guinea Bissau within health screening project in African countries during 2010 and 2011. This study discusses the impacts of surgical interventions on public health besides suggestions for non-governmental organizations and volunteers supporting rural surgery.

\section{MATERIALS AND METHODS}

Surgical interventions performed by a volunteer group of surgeons from the DWW Turkey in Simao Mendes, Gabu and Bafata community hospitals of Guinea-Bissau from 5 to 16 February 2010, and 6 to 11 May 2011 were included in this study. Demographic features of the patients such as age and gender were recorded. Patients were grouped according to their status as candidates for emergency or elective surgery. Type and status of hernias (recurrent, bilateral, reducible, strangulated, obstructed), localization of masses, preferred surgical and anesthesia techniques as well as postoperative complications were documented.

\section{RESULTS}

Twenty four patients underwent 27 surgical procedures between 5-16 February 2010 (Table 1). Variety of surgical interventions with different diagnoses were undertaken on 18 (75\%) male and $6(25 \%)$ female patients. Mean age was 43.8 years (range: 7-81 yrs). Two patients were considered for emergency operations. Hartmann's procedure for locally advanced rectal cancer, modified radical mastectomy for breast cancer, right total thyroidectomy for nodular goitre, and mesh repair for an incisionel hernia were performed. Inguinal hernias of the patients, were bilateral $(n=1)$, and strangulated $(n=2)$ or coexisted with hydrocele. One bilateral Liechtenstein and one left Liechtenstein procedure with right inguinal darn repair were performed for the cases with bilateral inguinal hernia. Two strangulated hernia patients underwent Liechtenstein hernioplasty. Eight hernia patients underwent darn repair, for other hernia patients Liechtenstein hernioplasty $(n=1)$, high ligation $(n=1)$, Bassini repair $(n=1)$, and herniectomy $(n=1)$ were performed. Synchronous Winkelmann's procedure was performed for 1 patient who also had darn repair. Also, local excision of a breast mass $(n=1)$, Winkelmann's hydrocelectomy excision $(\mathrm{n}=1)$ of a local cutaneous mass $(n=1)$, and keloid excision $(n=1)$ were carried out. The patients received general $(n=12 ; 17.6 \%)$, spinal $(n=4 ; 5.9 \%)$, epidural $(n=7 ; 10.3)$, ketamine $(\mathrm{n}=1 ; 1.5 \%)$, and local $(\mathrm{n}=8 ; 11.8 \%)$ anesthesia. 
TABLE 1. Surgical procedures between 5-16 February 2010 in Guinea-Bissau

\begin{tabular}{|c|c|c|c|c|c|}
\hline Date & Gender & Age & Diagnosis & Operation & Anesthesia \\
\hline February 5 & M & 45 & Bilateral inguinal hernia & $\begin{array}{l}\text { L Liechtenstein } \\
\mathrm{R} \text { darn repair }\end{array}$ & Spinal \\
\hline February 5 & M & 42 & $\begin{array}{l}\text { L strangulated inguinal } \\
\text { hernia (no necrosis) }\end{array}$ & Liechtenstein & General \\
\hline February 8 & M & 7 & $\mathrm{R}$ indirect inguinal hernia & High ligation & General \\
\hline February 8 & $\mathrm{~F}$ & 27 & R goitre & $\mathrm{R}$ total thyroidectomy & General \\
\hline February 8 & M & 30 & $\mathrm{R}$ indirect strangulated hernia & Liechtenstein & General \\
\hline February 9 & M & 81 & $\mathrm{R}$ indirect inguinal hernia & Darn repair & Spinal \\
\hline February 9 & $\mathrm{~F}$ & 26 & R submandibular mass & Excision & Local \\
\hline February 9 & $\mathrm{~F}$ & 56 & $\begin{array}{c}\text { Rectal carcinoma with invasion } \\
\text { of vagina and anus }\end{array}$ & Hartmann's procedure & General \\
\hline February 11 & M & 19 & $\mathrm{R}$ inguinal hernia & Darn repair & Spinal \\
\hline February 11 & M & 21 & Umbilical keloid & Excision & Local \\
\hline February 11 & $\mathrm{~F}$ & 22 & Incisionel hernia & Mesh repair & General \\
\hline February 12 & M & 45 & Bilateral direct inguinal hernia & Bilateral Liechtenstein & Spinal \\
\hline February 12 & $\mathrm{~F}$ & 23 & $\mathrm{R}$ lateral breast mass & Mass excision (benign) & Local \\
\hline February 13 & M & 75 & L scrotal hernia & Liechtenstein & $\begin{array}{l}\text { Ilioinguinal blockade, } \\
\text { superficial general }\end{array}$ \\
\hline February 13 & M & 67 & R hydrocele & Winkelmann's procedure & $\begin{array}{l}\text { Ilioinguinal blockade, } \\
\text { superficial general }\end{array}$ \\
\hline February 13 & M & 60 & R direct hernia, $L$ hydrocele & Darn repair, Winkelmann's procedure, & Single dose epidural \\
\hline February 15 & M & 58 & $\mathrm{R}$ recurrent scrotal hernia & Primary repair, Bassini & $\begin{array}{l}\text { Single dose epidural, } \\
\text { sedation }\end{array}$ \\
\hline February 15 & M & 55 & R sliding hernia & $\begin{array}{l}\text { Partial herniectomy, reduction to } \\
\text { abdomen, plication, darn repair }\end{array}$ & $\begin{array}{l}\text { Ilioinguinal blockade, } \\
\text { superficial general }\end{array}$ \\
\hline February 15 & M & 58 & $\mathrm{~L}$ direct hernia & Reduction, plication, darn repair & Single dose epidural \\
\hline February 15 & M & 26 & $\mathrm{R}$ direct hernia & $\begin{array}{l}\text { Herniectomy, plication, } \\
\text { darn repair }\end{array}$ & $\begin{array}{c}\text { Ilioinguinal blockade, } \\
\text { superficial general, } \\
\text { epidural }\end{array}$ \\
\hline February 15 & M & 73 & $\mathrm{~L}$ indirect scrotal hernia & $\begin{array}{l}\text { Herniectomy, plication, } \\
\text { darn repair }\end{array}$ & $\begin{array}{c}\text { Epidural, ketamine, } \\
\text { morphin, superficial } \\
\text { general }\end{array}$ \\
\hline February 16 & M & 21 & $\mathrm{R}$ indirect inguinal hernia & Herniectomy, plication, darn repair & Epidural, sedation, local \\
\hline February 16 & M & 70 & $L$ indirect inguinal hernia & Herniectomy, plication, darn repair & Single dose epidural \\
\hline February 16 & $\mathrm{~F}$ & 45 & Left breast carcinoma & MRM & General \\
\hline
\end{tabular}

M: Male; F: Female; R: Right; L: Left; MRM: Modified radical mastectomy.

Thirty three patients underwent 37 surgical procedures between 6-11 May 2011 (Table 2). Mean age was 45.1 years (range: $6-80$ ) and there were 29 male $(87.9 \%)$ and 4 female $(12.1 \%)$ patients. Three patients underwent emergency operations. Of 19 inguinal hernias, 2 were bilateral and recurrent, 1 was strangulated, and 2 were recurrent. Cases with inguinal hernia $(n=15)$ underwent Liechtenstein procedure $(n=1)$, darn repair $(n=1)$, while pediatric hernia patients underwent high ligation $(n=2)$, and one case with recurrent hernia underwent mesh plug repair. One of the 6 cases with hydrocele was 
TABLE2. Surgical procedures between 6-11 May 2011 in Guinea-Bissau

\begin{tabular}{|c|c|c|c|c|c|}
\hline Date & $\begin{array}{l}\text { Age } \\
\text { (yrs) }\end{array}$ & Gender & Diagnosis & Operation & Anesthesia \\
\hline May 6, 2011 & 72 & M & $\begin{array}{l}\text { Bilateral recurrent inguinal hernia } \\
\quad \text { (R Amyand's hernia) }\end{array}$ & Liechtenstein & Spinal \\
\hline May 6, 2011 & 24 & M & Bilateral recurrent inguinal hernia & Darn repair & $\begin{array}{l}\text { Spinal } \\
\text { Ketalar }\end{array}$ \\
\hline May 6, 2011 & 22 & M & $L$ inguinal hernia & Liechtenstein & Spinal \\
\hline May 7, 2011 & 68 & M & $\mathrm{R}$ inguinal hernia & Liechtenstein & Spinal \\
\hline May 7, 2011 & 26 & M & R inguinal hernia (strangulated) & Liechtenstein & Spinal \\
\hline May 7, 2011 & 60 & M & Grynfeltt hernia & Mesh repair & Spinal \\
\hline May 7, 2011 & 13 & M & Plastron appendicitis & Drainage & General \\
\hline May 7, 2011 & 29 & M & Nodular goitre & R lobectomy & General \\
\hline May 7, 2011 & 32 & $\mathrm{~F}$ & $\begin{array}{l}\text { Incisionel hernia+umbilical hernia } \\
\text { (Post cesarian section) }\end{array}$ & Mesh repair+primary repair & Spinal \\
\hline May 8, 2011 & 60 & M & $\mathrm{R}$ inguinal hernia & Liechtenstein & Spinal \\
\hline May 8, 2011 & 60 & M & $\mathrm{R}$ inguinal hernia & Liechtenstein & Spinal \\
\hline May 8, 2011 & 43 & M & RLQ cyst & Total excision & Local \\
\hline May 8, 2011 & 14 & M & Acute appendicitis & Appendectomy (Pararectal incision) & General \\
\hline May 8, 2011 & 35 & $\mathrm{~F}$ & Multi noduler goitre & Bilateral subtotal thyroidectomy & General \\
\hline May 8, 2011 & 20 & M & $\mathrm{L}$ recurrent inguinal hernia & Liechtenstein & Spinal \\
\hline May 9, 2011 & 80 & M & $\mathrm{L}$ inguinal hernia & Liechtenstein & Spinal \\
\hline May 9, 2011 & 60 & M & $L$ inguinal hernia & Liechtenstein & Spinal \\
\hline May 9, 2011 & 65 & M & $L$ inguinal hernia & Liechtenstein & Local \\
\hline May 9, 2011 & 58 & M & $\begin{array}{l}\text { L inguinal hernia } \\
\text { L hydrocele }\end{array}$ & $\begin{array}{l}\text { Liechtenstein } \\
\text { Winkelmann's procedure }\end{array}$ & $\begin{array}{l}\text { Spinal } \\
\text { Ketalar }\end{array}$ \\
\hline May 9, 2011 & 70 & M & $\mathrm{R}$ hydrocele & R orchiectomy & Spinal \\
\hline May 10, 2011 & 30 & M & $L$ inguinal hernia & Liechtenstein & Local \\
\hline May 10, 2011 & 30 & M & $\mathrm{R}$ recurrent inguinal hernia & Mesh plug repair & $\begin{array}{l}\text { Local } \\
\text { Ketalar }\end{array}$ \\
\hline May 10, 2011 & 57 & M & $\mathrm{R}$ hydrocele & Winkelmann's procedure & $\begin{array}{l}\text { Local } \\
\text { Ketalar }\end{array}$ \\
\hline May 10, 2011 & 70 & M & $\mathrm{R}$ inguinal hernia & Liechtenstein & Spinal \\
\hline May 10, 2011 & 59 & M & L hydrocele & Winkelmann's & Spinal \\
\hline May 10, 2011 & 80 & M & Bilateral hydrocele & $\begin{array}{c}\text { R orchiectomy } \\
\text { L Winkelmann's procedure }\end{array}$ & Spinal \\
\hline May 10, 2011 & 65 & M & $\mathrm{R}$ inguinal hernia $(\mathrm{HIV}+)$ & Liechtenstein & Spinal \\
\hline May 10,2011 & 62 & $\mathrm{~F}$ & Lipoma & Local excision & Local \\
\hline May 10, 2011 & 65 & M & R hydrocele & Winkelmann's procedure & Spinal \\
\hline May 11, 2011 & 16 & $\mathrm{~F}$ & Lower extremity keloid & Excision (corticosteroid topical therapy) & Local \\
\hline May 11, 2011 & 6 & M & $\mathrm{R}$ inguinal hernia & High ligation & Ketalar \\
\hline May 11, 2011 & 9 & M & $\mathrm{R}$ inguinal hernia & High ligation & Ketalar \\
\hline
\end{tabular}

M: Male; F: Female; R: Right; L: Left; RLQ: Right lower quadrant; IM: Intramuscular.

bilateral (underwent unilateral orchiectomy), and 1 coexisted with ipsilateral inguinal hernia (all underwent Winkelmann's procedure). Multinodular goi- ter was recorded in 2 patients (bilateral subtotal and unilateral) who underwent total thyroidectomy. $\mathrm{Pa}$ tients received spinal $(n=19 ; 27.9 \%)$, general $(n=4$; 
$5.9 \%)$, ketamine $(\mathrm{n}=6 ; 8.8 \%)$, and local anesthesia $(\mathrm{n}=7 ; 10.3 \%)$ during the procedures. There was no mortality due to either surgery, or anesthesia.

\section{DISCUSSION}

People are not born to the same and equal circumstances and opportunities in the world. In some regions of the world, people live well in prosperity using ultimate technology, while in other regions they struggle in poverty. For instance, still today, more than 2 million people are unable to receive surgical treatment. Guinea-Bissau is one of the most underdeveloped and poverty-stricken 25 countries of the world in Africa, with an approximate population of 1.7 million.

Majority of the deaths in Guinea-Bissau are related with surgical diseases where surgical facilities are inaccessible. In order to overcome the handicaps against effective surgical care, strategies which focus on reassuring financial sources and timely surgical interventions should be established [5].

Anesthesiology is provided by advanced technological facilities as well as specialized professional teams in the developed countries. Sophisticated anesthesiology equipments are obviously safer, however, they are costly and their technical maintenance and repair cause additional expenses. Without any doubt, in low income countries such as GuineaBissau, financial sources dedicated for health care are very limited. Managing surgical interventions under local anesthesia when feasible (i. e. hernia, hydrocele), would definitely decrease the expenses for anesthesia [6]. Our surgical operations within these series have been performed under general anesthesia ( $n=16$ patients; $28.1 \%$ ), spinal anesthesia $(n=24 ; 42.1 \%)$, epidural anesthesia $(n=5 ; 8.8 \%)$, local anesthesia $(n=10 ; 17.5 \%)$, and IM ketalar anesthesia $(n=2 ; 3.5 \%)$ without complications.

Sub-Saharan countries of Africa possess only $2 \%$ of the medical aid sources of the world, while suffering from $25 \%$ of the disease load of the globe. In East Africa, there is only 1 surgeon per 400.000 population. In some African countries, there is only 1 anesthesiologist per 1 million population. Obviously, in such circumstances, prompt training of new nurse anesthesia specialists is mandatory. In addition, in order to promote the suboptimal working environment, health care strategies which allow easy procurement of technical equipments and storage of essential agents such as oxygen, anesthetics and other essential pharmaceutical products must be reinforced by several maneuvers.

Traumatic injuries and obstetric emergencies are major causes of morbidity and mortality which in fact can be readily prevented by surgical interventions. Several lines of evidence documented that surgical circumstances such as injuries, obstetric emergencies and congenital anomalies are serious public health issues [7]. In addition, as it was observed, basic surgical services could be provided at a reasonable margin in countries with low and middle income. In 2004, various subgroups of World Health Organization (WHO) started working on surgical diseases and since 2008 surgical diseases have been considered as a prerequisite for the primary health care services [8]. Majority of the patients in our series had the most commonly seen surgical diseases such as hernia and hydrocele $(61.4 \%$ : inguinal hernias, $8.7 \%$ : hydroceles).

According to WHO 25 physicians per 10.000 of population would be sufficient [9]. World Health Organization suggests 1 general surgeon per 13.250 individuals [10]. This rate is 1:400.000 in Uganda, and 1:2 million in North Somalia. Again, WHO suggests that sufficient primary health care can be provided by 23 health care workers per 100.000 individuals (physician, nurse and delivery nurse), however, this ratio is far lower in most African countries $[11,12]$. Moreover, mortality due to anesthesia in some of the African countries is as high as $1: 150$ [13].

Although, many diseases can be curable and deaths preventable by surgical treatment, surgical diseases have long been considered on an individual basis separate from the global public health issues [14]. This may be due to the fact that surgical diseases are not contagious. Another argument could be that surgeons were often indifferent to public health issues. Finally, surgery comprises of more sophisticated context compared to other medical specialties. Apart from the surgeon, pursuing a surgical procedure necessitates an anesthesiology specialist, 
an operating room, sterilization facilities, surgical instruments, postoperative care and blood bank for selected cases. Moreover, traffic accidents, work-related accidents (agriculture workers), peritonitis, fractures and blindness are other remarkable surgical challenges and in fact, they are often curable. In the underdeveloped countries, surgical services are mostly accessible only in the urban areas and in contrast to the infectious diseases, achieving surgical services is even easier when the patient meets the expenses.

Blitz surgery focuses on specific fields and it is an efficient model for aid campaigns. Usual duration of this service is less than 3 weeks. Blitz surgery is an efficient service mostly brought by non-governmental organizations from wealthy to underdeveloped countries and predominantly deals with the patients of reconstructive surgery [12]. The focus is often on the treatment of particular group of diseases (cleft lip-palate) instead of training local surgeons. This results with the continuing dependency of the mentioned countries on developed ones as well as unsolved difficulties in preoperative and especially postoperative patient care. Tendency towards completing multiple operations within a limited period may obviously downscale the surgical quality. Furthermore, surgeons may have to operate the patients with diseases unrelated to their specialty fields and assistant surgeons may have to operate by themselves. However, in spite of all limitations, blitz surgery is an efficient temporary solution. Inviting the local African surgeons to the developed countries for training for certain periods will improve the quality of surgical services when they return home. Another solution might be supporting the reverse brain drain of the African surgeons who had immigrated to developed countries [15].

Establishing long-term collaboration between hospitals of developed and underdeveloped countries would lead to gradual and permanent improvement of the health care services. Experience share by periodical physician exchange not only provides a 'boot camp' for the less trained, but offers an occasion for the more sophisticated surgeons to selfcriticize and also deliver qualified surgical services to the communities in poverty as well [16]. In addition, this also helps to improve constitutional problems of the hospitals. Operating rooms, sterilization units, postoperative care units, blood banks, anesthesia equipments and laboratories should be promoted.

Working in rural areas where all facilities are limited or even sometimes completely absent, ironically brings acquirements in multiple aspects, both to the visiting surgeon(s) and the local team, as well as the rural community. Visiting surgeon develops new skills in order to work in restricted circumstances, while the local surgeon learns new techniques and procedures; finally, the most important achievement will be delivering solutions for the diseases of the local community [17]. Even a single complication which is not well-managed can overshade thousands of masterpiece operations. In order to prevent complications, surgical cases must be well planned in terms of procedures, teams and instrumentation and strenuous cases should not be rushed. Good communication with the local physicians must be maintained and they must be encouraged to take part in the operations.

During the patient follow-up, local physicians must be taught to take full responsibility. Visiting surgeons must be aware of the skills of the medical team and prefer surgical techniques suitable for the rural area. Minimally invasive procedures, which would require relatively shorter follow-up periods must be preferred if possible, and emphasis must be placed on the quality of the surgeries rather than their quantity. Pursuing any commercial competition with other relief organizations must be avoided during such services. Commitment to a continuous mission with preferably same workforce has a paramount importance. Ongoing collaboration with the local team, periodic calibration of all equipment and supplies, regular patient follow-ups also have utmost importance in restoring sustainable health care in the rural areas.

To sum up, surgical services in underdeveloped regions of the world can be improved with continuous and committed collaboration of the workforces. Blitz surgery is an efficient way to start with.

\section{Acknowledgements}

We thank all the health workers in Simao Mendes, 
Gabu and Bafata community hospitals for their great effort and hospitality in this team work.

Conflict of Interest: No conflict of interest was declared by the authors.

Funding Resources: Doctors Worldwide (DWW), Republic of Turkey Ministry of Health, Turkish Collaboration and Development Department carried a collaborative act in the financial support of this project.

\section{REFERENCES}

1. Farmer PE, Kim JY. Surgery and global health: a view from beyond the OR. World J Surg 2008;32:533-6.

2. Assessment of medicines regulatory systems in sub-Saharan African countries: An overview of findings from 26 assessment reports. World Health Organization 11.12.2010.

3. Perkins RS, Casey KM, McQueen KA. Addressing the global burden of surgical disease: proceedings from the 2 nd annual symposium at the American College of Surgeons World J Surg 2010;34:371-3.

4. Ozgediz D, Riviello R. The "other" neglected diseases in global public health: surgical conditions in sub-Saharan Africa. PLoS Med 2008;5:e121.

5. Grimes CE, Law RS, Borgstein ES, Mkandawire NC, Lavy CB. Systematic review of met and unmet need of surgical disease in rural sub-Saharan Africa. World J Surg 2012;36:8-23.

6. Irabor DO. Hernia repair under local or intravenous Ketamine in a tropical low socio-economic population. West Afr J Med 2005;24:143-6.

7. Chu K, Maine R, Trelles M. Cesarean section surgical site infec- tions in sub-Saharan Africa: a multi-country study from Medecins Sans Frontieres. World J Surg 2015;39:350-5.

8. Chirdan LB, Ameh EA. Untreated surgical conditions: time for global action. Lancet 2012;380:1040-1.

9. Drain PK, Primack A, Hunt DD, Fawzi WW, Holmes KK, Gardner P. Global health in medical education: a call for more training and opportunities. Acad Med 2007;82:226-30.

10. Global Initiative for Emergency and Essential Surgical Care (GIEESC). World Health Organization (2012) http://www. who.int/surgery/globalinitiative/en/.

11. Luboga S, Macfarlane SB, von Schreeb J, Kruk ME, Cherian $\mathrm{MN}$, Bergström $\mathrm{S}$, et al. Increasing access to surgical services in sub-saharan Africa: priorities for national and international agencies recommended by the Bellagio Essential Surgery Group. PLoS Med 2009;6:e1000200.

12. Nthumba PM. “Blitz surgery": redefining surgical needs, training, and practice in sub-Saharan Africa. World J Surg 2010;34:433-7.

13. Pollach G. Anaesthetic-related mortality in sub-Saharan Africa. Lancet 2013;381:199.

14. Tomlinson J, Haac B, Kadyaudzu C, Samuel JC, Campbell EL, Lee $\mathrm{CN}$, et al. The burden of surgical diseases on critical care services at a tertiary hospital in sub-Saharan Africa. Trop Doct 2013;43:27-9.

15. Ncayiyana D. Doctor migration is a universal phenomenon. $\mathrm{S}$ Afr Med J 1999;89:1107.

16. Chen L, Evans T, Anand S, Boufford JI, Brown H, Chowdhury $\mathrm{M}$, et al. Human resources for health: overcoming the crisis. Lancet 2004;364:1984-90.

17. Pollock JD, Love TP, Steffes BC, Thompson DC, Mellinger J, Haisch C. Is it possible to train surgeons for rural Africa? A report of a successful international program. World J Surg 2011;35:493-9. 